
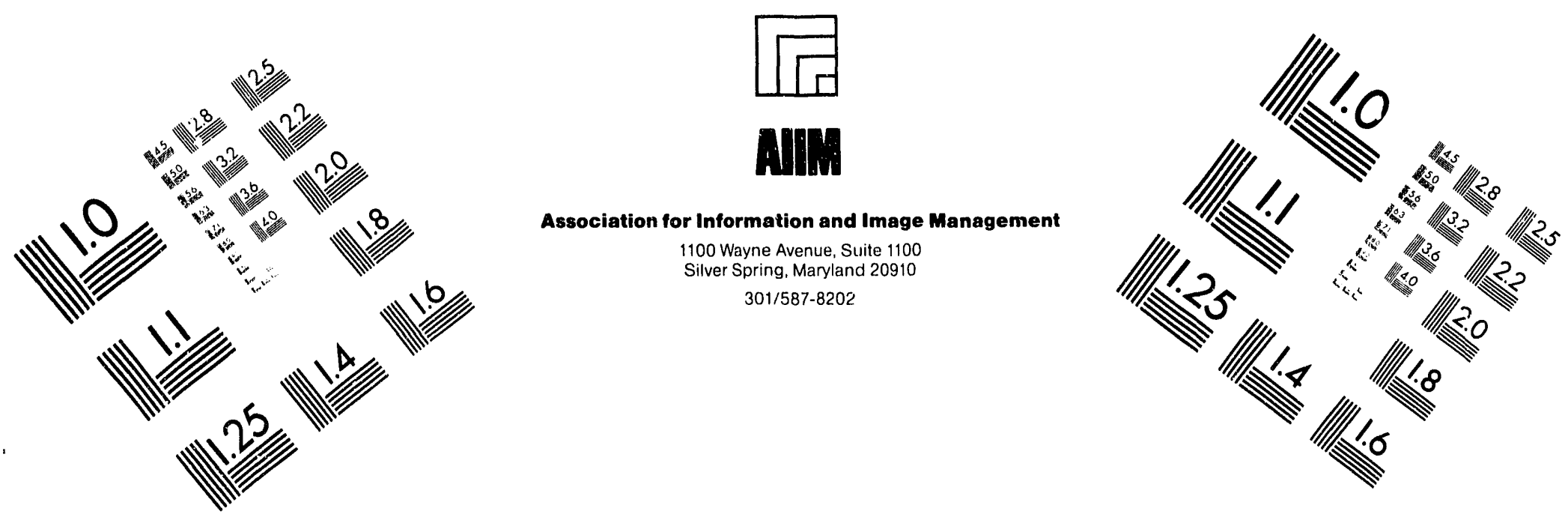

\title{
Centimeter
}

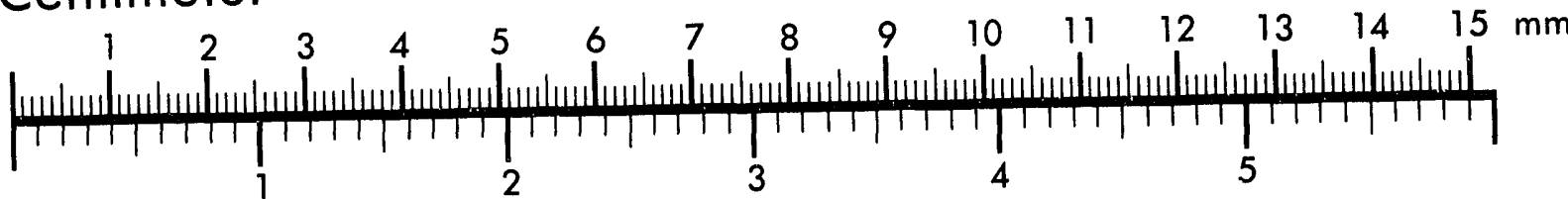
Inches
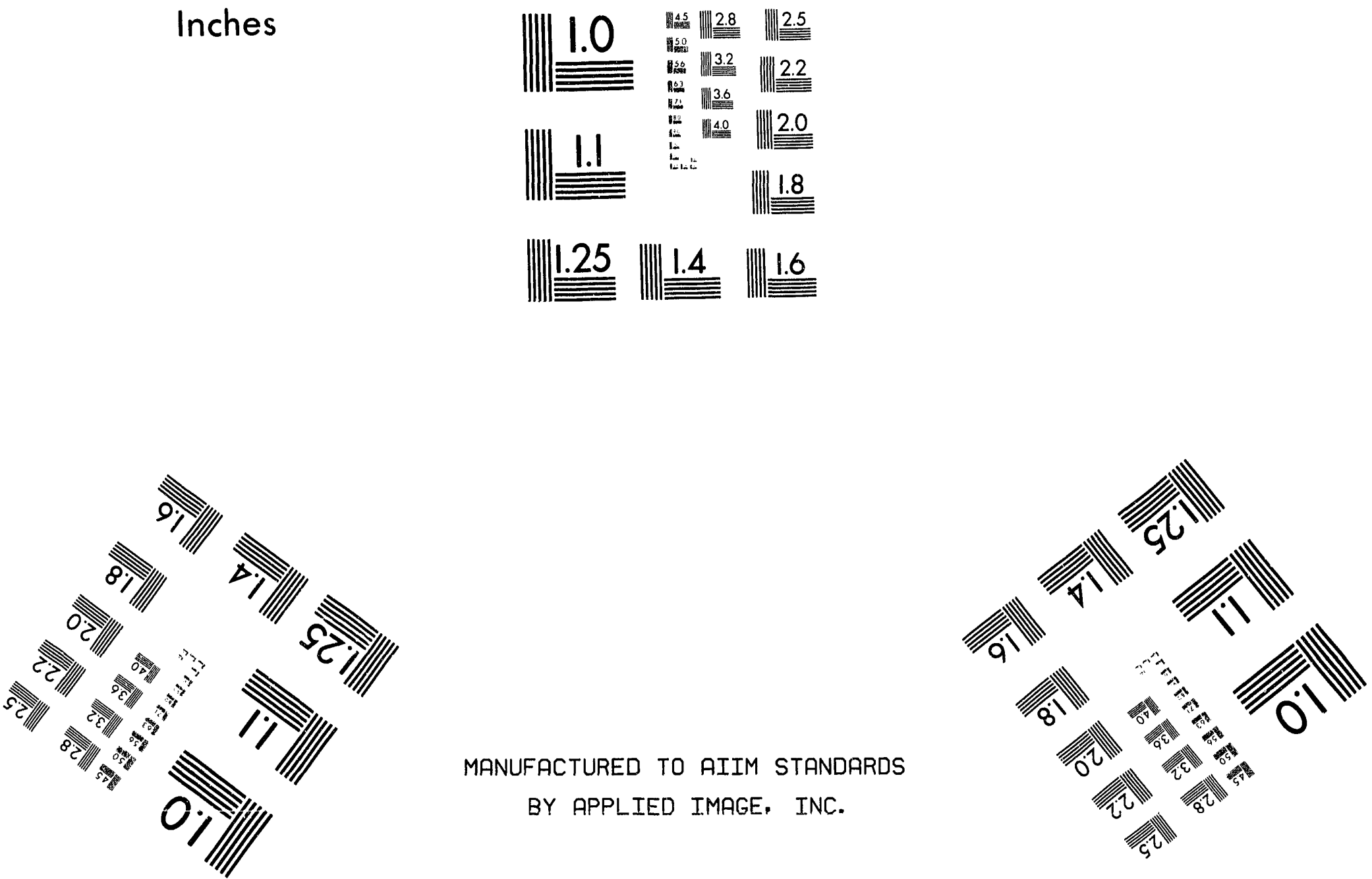

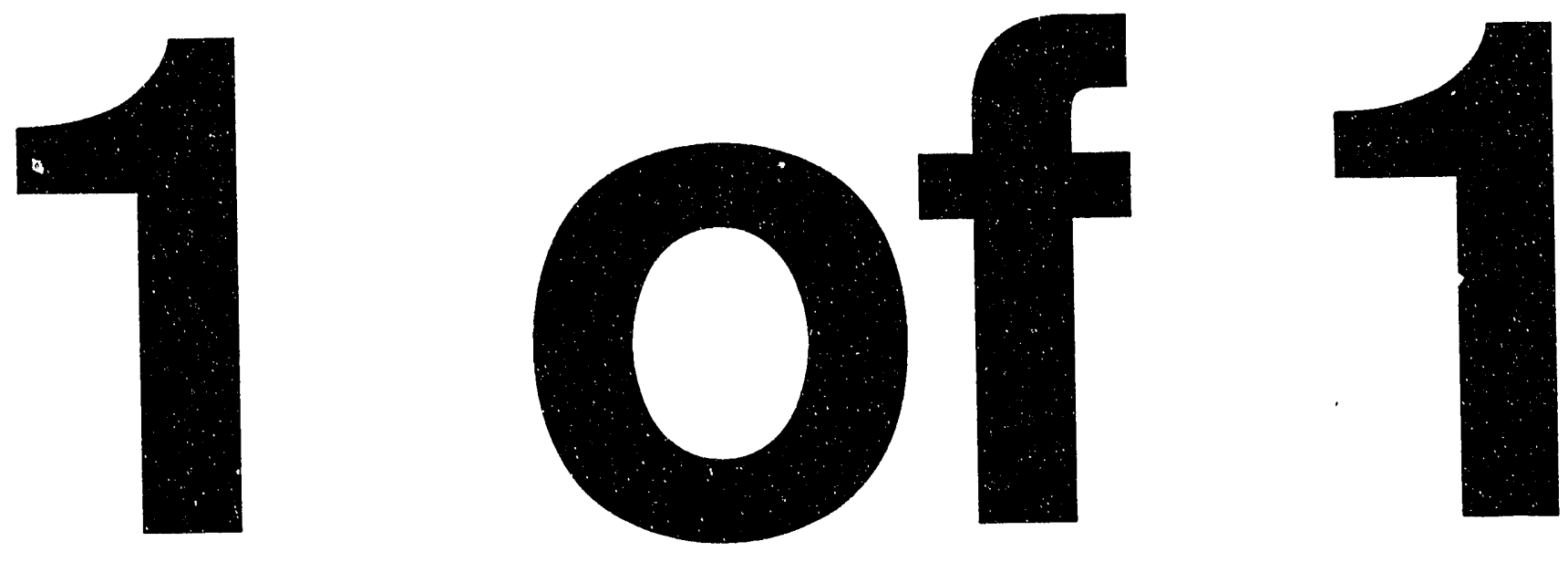
KEY WORDS: Computer Model

Gas Generation

Curie Limit

Transuranic Waste Drums

RETENTION PERIOD: LIFETIME

\section{Revisions to the Hydrogen Gas Generation Computer Model (U)}

By

J. W. Jerrell

ISSUED: August 31, 1992

SRTC SAVANNAH RIVER TECHNOLOGY CENTER, AIKEN, SC, 29808 Westinghouse Savannah River Company

Prepared for the U. S. Department of Energy under Contract DE-AC09-89SR18035

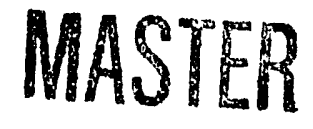

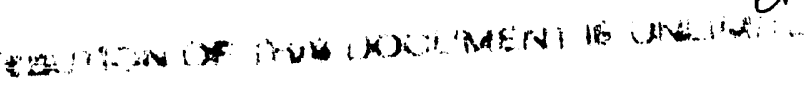




\section{DOCUMENT: $\quad$ WSRC-TR-92-421}

\section{TITLE: Revisions to the Hydrogen Gas Generation Computer Model (U)}

\section{APPROVALS}

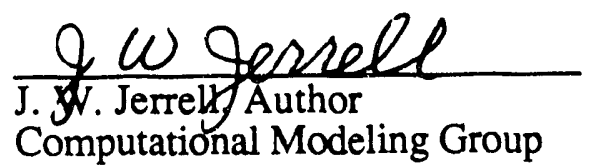

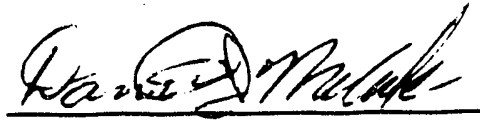

D. J. McCabe, Customer

Interim Waste Technology

Le Deyrey

J. R. Pelfrey, hanager

Computational Modeling Group

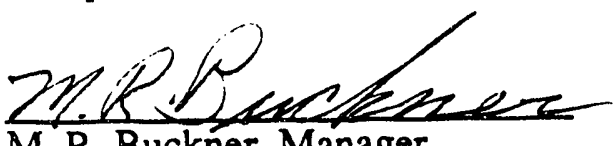

M. R. Buckner, Manager

Scientific Computations Section
D A T E : $9-1-92$

D A T E: $9-3-92$

D A T E : $9-\angle 7-42$ 


\section{DISCLAIMER}

This report was prepared as an account of work sponsored by an agency of the United States Government. Neither the United States Government nor any agency thereof, nor any of their employees, makes any warranty, express or implied, or assumes any legal liability or responsibility for the accuracy, completeness, or usefulness of any information, apparatus, product, or process disclosed, or represents that its use would not infringe privately owned rights. Reference herein to any specific commercial product, process, or service by trade name, trademark, manufacturer, or otherwise does not necessarily constitute or imply its endorsement, recommendation, or favoring by the United States Government or any agency thereof. The views and opinions of authors expressed herein do not necessarily state or reflect those of the United States Government or any agency thereof.

This report has been reproduced directly from the best available copy.

Available to DOE and DOE contractors from the Office of Scientific and Technical Information, P.O. Box 62, Oak Ridge, TN 37831; prices available from (615) 576-8401, FTS 626-8401.

Available to the public from the National Technical Information Service, U.S. Department of Commerce, 5285 Port Royal Rd., Springfield, VA 22161. 


\section{CONTENTS}

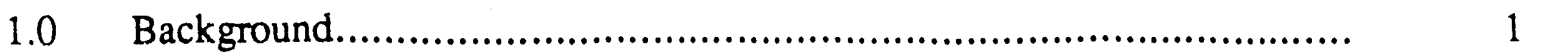

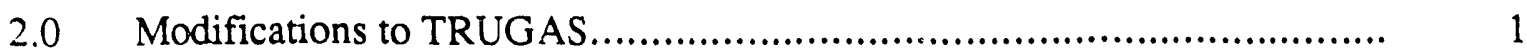

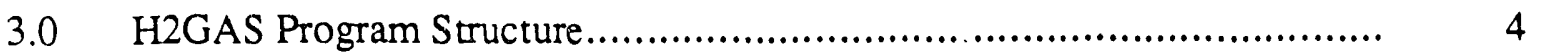

4.0 Illustrative Examples....................................................................

$5.0 \quad$ Quality Assurance.................................................................... 5

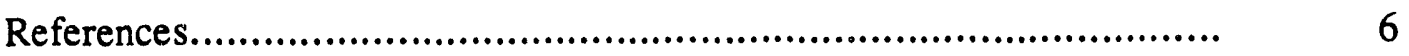

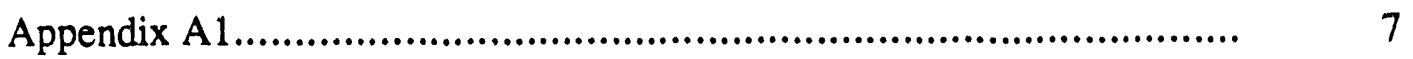

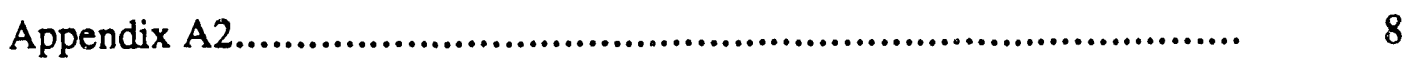

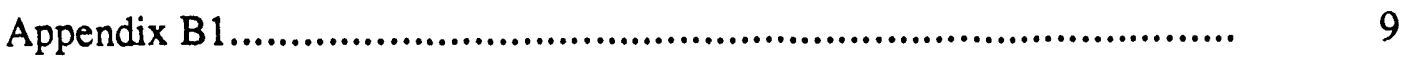

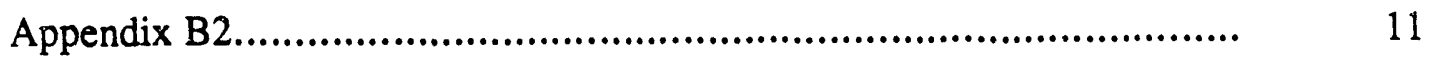

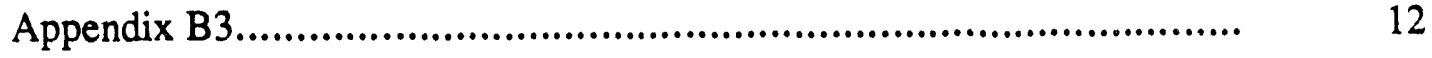

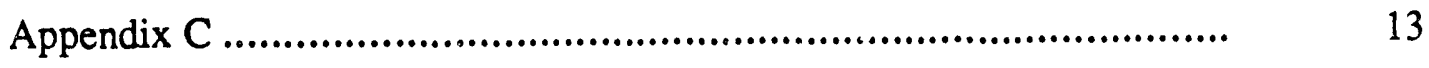

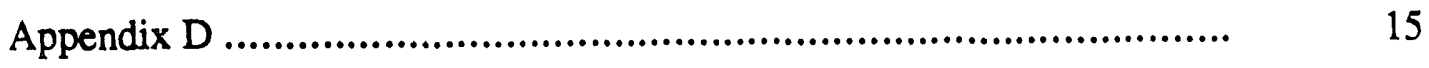

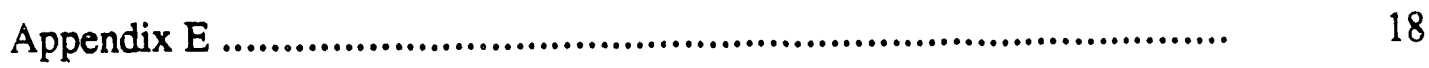

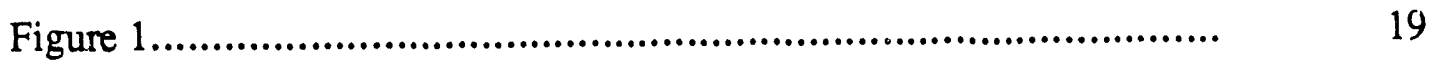

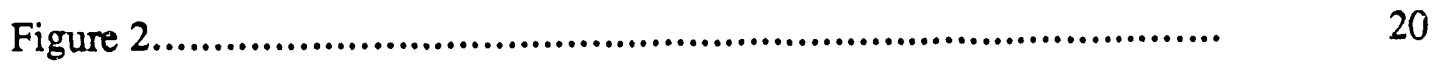

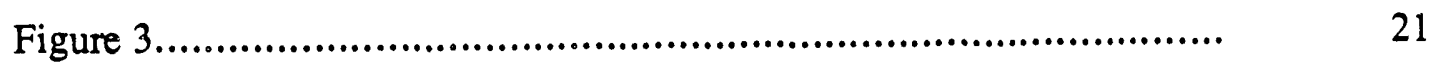

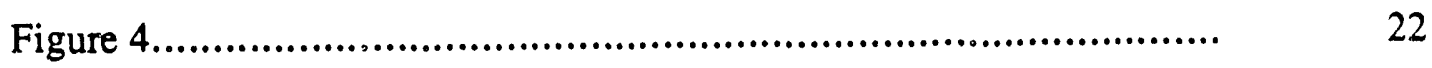


1.0 Background

Waste Management Technology has requested SRTC to maintain and extend a previously developed computer model, TRUGAS, which calculates hydrogen gas concentrations within the transuranic (TRU) waste drums. TRUGAS was written by Frank G. Smith using the BASIC language and is described in the report A Computer Model of gas Gineration and Transport within TRU Waste Drums (DP-1754). The computer model has been partially validated by yielding results similar to experimental data collected at SRL and LANL over a wide range of conditions.

The model was created to provide the capability of predicting conditions that could potentially lead to the formation of flammable gas concentrations within drums, and to assess proposed drum venting methods. The model has served as a tool in determining how gas concentrations are affected by parameters such as filter vent sizes, waste composition, gas generation values, the number and types of enclosures, water instrusion into the drum, and curie loading.

The success of the TRUGAS model has prompted an interest in the program's maintenance and enhancement. Experimental data continues to be collected at various sites on such parameters as permeability values, packaging arrangements, filter designs, and waste contents. Information provided by this data is used to improve the accuracy of the model's predictions. Also, several modifications to the model have been made to enlarge the scope of problems which can be analyzed. For instance, the model has been used to calculate hydrogen concentrations inside steel cabinets containing retired glove boxes (WSRC-RP-89-762).

The revised TRUGAS computer model, H2GAS, is described in this report. This report summarizes all modifications made to the TRUGAS computer model and provides documentation useful for making future updátes to H2GAS.

\subsection{Modifications to TRUGAS}

Fifteen major modifications have been made to TRUGAS:

1. TRUGAS was created in BASIC and intended for execution on IBM Personal Computers. The first modification to TRUGAS was a direct translation into ANSI standard FORTRAN to allow execution on the VAX cluster (VMS) or IBM mainframe (VM). No program modifications were made during this translation other than those necessary for the code to run successfully.

2. TRUGAS was designed primarily as an interactive program. It requires the user to review each input into the program and to respond 'yes' or 'no' when queried as to the correctness of the entry. An incorrect entry can be modified.

H2GAS, the FORTRAN version, utilizes an input data file and interactive questions as the methods of data entry. Editors on the VAX, such as JED and EDT, can be used to construct and modify the input file. Appendix A1 is an example execution of H2GAS. The user is prompted by the program for the following:
a. input data filename (example in Appendix A2);
b. output pressure results filename (example in Appendix B1);
c. 'yes' or 'no' to freeze display of results and halt run after every ten printout time steps;
d. 'yes' or 'no' to change filter porosity at a specified time;
e. 'yes' or 'no' to modify gas generation $\mathrm{G}$ values. 
All other input is entered into the input data file illustrated in Appendix A2. This information includes:
a. Relative weights of waste composition;
b. Curie loading;
b. Number of enclosures;
c. Volume, area, thickness, and type of enclosure barriers;
d. Area, thickness, and porosity of filters, if any;
e. Existence of hydrogen recombiners;
f. Day that filter porosity changes and the new filter porosity;
g. Pressure at which the drum top pops off of the drum;
h. Maximum time for transient calculations;
i. Time step for calcultions;
j. Number of hours between printouts;
k. Surface temperature of the drum;
1. Thermal conductivity of waste contents.

3. There are two primary agents of mass transport through each of the enclosures: permeation and diffusion. Diffusion occurs through the free air space, through the filters, and through holes in the enclosure materials. Permeation occurs as the gas is transported through the pores of the enclosure materials. An output file narned flux.dat shows the magnitudes and relative percentages of gas transport attributed to diffusion and permeation. Appendix B2 shows a representative gas flux output file.

The first column of the output file shows the calculated hydrogen gas flux in moles $/ \mathrm{hr}-\mathrm{ft}^{2}$ for each enclosure. The second column, titled H2 Transport Agents, consists of three sub-columns: Permeation; Diffusion (material); and Diffusion (filter). Relative percentages show the contribution of each of the three paths to gas transport.

This output file was added as a diagnostic tool to aid in understanding the agents responsible for gas transport under various conditions. For example, an enclosure such as a plywood box would have a high porosity and diffusion would act as the primary hydrogen gas transport agent. Small changes in parameters affecting the calculated permeability of the wood would have little effect on the hydrogen gas concentration. Efforts, then, to bring the model calculations in line with experimental results would focus on porosity values affecting diffusion rather than values affecting permeation.

4. The number of enclosures alluwed in TRUGAS is five. Changes to the packaging of waste have necessitated that the maximum number of allowable enclosures be increased. The maximum number of enclosures has been increased to fifteen.

5. Temperature affects the gas calculations in two ways. First, the gas concentration in each enclosure is calculated with the ideal gas law. Secondly, gas transport across the enclosure barrier depends upon the rate of gas diffusion which is affected by temperature.

Temperature in TRUGAS is assumed to be constant at $77^{\circ} \mathrm{F}$. In H2GAS the average drum temperature is calculated from the enviromental temperature, Curie loading, and thermal conductivity of the waste inside of the drum.

Accurately calculating temperatures of transuranic waste is difficult due to the poorly defined character of the waste. Experimental results from Sandia National Laboratory showed that a typical TRU waste drum has a thermal conductivity of between 0.02 to $0.04 \mathrm{Btu} / \mathrm{hr}-\mathrm{ft}^{\circ} \mathrm{F}$ depending upon the waste form (1). Thermal conductivity can vary greatly from one analysis to the next and is an input supplied by the user. 
H2GAS considers the transuranic waste to be distributed uniformly throughout an infinitely long cylinder with $\mathrm{Pu}-238$ as the heat source. The integral average temperature is computed within the cylindrical volume and assumed to be the same for all regions inside the drum. This temperature is substituted into the ideal gas law to calculate concentrations. The temperature dependent gas transport diffusion coefficients are calculated using the Chapman-Enskog equation as modified by Fuller (2). The gas transport equations are then solved for partial pressures with the Crank-Nicholson scheme as found in TRUGAS.

H2GAS generates an output file named tout.dat which shows the average and centerline drum temperatures in addition to the input data used to calculate these temperatures. The drum average temperature is used to calculate gas concentrations because the average temperature best represents the temperature throughout the entire drum. The centerline temperature is calculated and printed. An example temperature output file is included as Appendix B3.

6. The hydrogen gas concentrations are highly dependent upon the gas generation $G$ values, the molecules of gas produced per $100 \mathrm{eV}$ of absorbed radiation, of the waste materials. Alpha radiation decomposes cellulose, polyethylene, latex, polyvinylchloride, plexiglass, and other organic materials in radiolysis reactions. Hydrogen, carbon monoxide, and carbon dioxide are produced by this process while oxygen is consumed. Experimental studies continue to update values for and methods of calculating $\mathrm{G}$ values.

TRUGAS and H2GAS both present the user with calculated $G$ values and request the user to verify that the calculated $G$ values are satisfactory. If the calculated values are not satisfactory TRUGAS terminates execution. The user then adjusts the waste composition matrix and executes TRUGAS again. H2GAS permits G values to be entered directly and interactively. The total $G$ value is then computed and printed to the screen. The user can modify $G$ values until they are acceptable.

7. Since filter areas are usually less than 1 square inch, the area for the filter data is now entered in square inches rather than in square feet.

8. Steady-state results are provided even when only transient results are requested, as the computer time used to perform the steady-state calculations is insignificant.

10. The effect of the radioactive decay of Pu-238 on the hydrogen gas generation rate for transient predictions has been included. Steady-state predictions from H2GAS assume that there is no radioactive decay of plutonium. Steady-state predictions, then, are conservative and show upper bounding concentrations.

11. The hydrogen gas generation values have been modified. The hydrogen $G$ value for the worse case loading of all polyethylene is 4.0 molecules of gas $/ 100 \mathrm{eV}$.

12. The format of the data printed to the terminal during the program execution has been modified to improve readability.

13. Output is additionally placed into a file named graph.dat. The first column contains the time of each prediction, and the remaining columns contain the mole percent of the hydrogen gas concentration for each enclosure, beginning with the first bag. This information can be placed into a spreadsheet and plotted.

14. The maximum hydrogen concentration in each enclosure and the time at which the concentration is reached appears at the bottom of the output file, as seen in Appendix B1. 
15. When the filter porosity was changed in TRUGAS at the specified day, the porosity was not correctly included in the diffusion equations as a squared term. This has been corrected in $\mathrm{H} 2 \mathrm{GAS}$.

H2GAS was written with an effort to allow future modifications to the program to be made efficiently. Subroutines have been created for code with unique identifiable functions, such as computing ' $G$ ' values, and adjusting flow due to the presence of filters. Twenty-three separate subroutines and the main calling program comprise H2GAS. Each subroutine is described by comments within the program listing, and is summarized in Attachmen: C. In upgrading TRUGAS to H2GAS subroutines have been deleted, converted and modified, or added as shown below:

Deleted

CHECK

NEWDATA

VOLUMES

CHANGE
Converted/Modified

PRNOUT

FILEOUT

WRITEOUT

READIN

FLOW

RUNDATA

SETUP

ANSWER

WRITEIN
New

MODGEN

FLUX

TEMP

DIFUS

MODGEN

FLAGMAT

DIFFVAL

STEADY

TRANSIENT

CRUNCH

RECOMB

SSORTR

DRUMEL

GVALU

The subroutines pass variables among themselves and the main program by named common blocks. Some variables are initialized in the main program by a block data statement; others are initialized in subroutine setup. All real variables are double precision. Appendix D lists all variables in $\mathrm{H} 2 \mathrm{GAS}$ along with their function and urits.

Some constants used in H2GAS required conversion from other units and are not easily recognized. These constants and their conversions are shown in Appendix E.

\subsection{Illustrative Examples}

The following results use input data from a typical waste drum, whose parameters are shown in Appendix A2, to provide an illustration of some of the capabilities of H2GAS. The curie loadings used are unrealistically high to emphasize the transient trends. The graph produced from the graph.dat output file shows the hydrogen concentration in the drum head space for each case.

Figure 1 shows the effect of the radioactive decay of plutonium-238 on the hydrogen concentration in the drum head space. The curve from TRUGAS shows the predicted hydrogen concentration over a time span of 15 years. H2GAS shows predicted hydrogen concentration over this same time span, but includes the effect of the decaying Pu-238. The half-life of the $\mathrm{Pu}-238$ is taken to be 86.4 years. To bring the curves into close agreement at the start of the transient, the hydrogen ' $G$ ' value was decreased in $\mathrm{H} 2 \mathrm{GAS}$ from 0.34 to 0.074 . The $0.34 \mathrm{G}$ value from $\mathrm{H} 2 \mathrm{GAS}$ is an updated value, but cannot be directly input into TRUGAS. 
The presence of hydrogen is significantly affected by the presence of a recombiner. Figure 2 demonstrates how the recombiner present in both the bags and liner decreases the hydrogen concentration. All hydrogen is combined with the oxygen to produced water until the supply of oxygen is exhausted. The recombiner can exist in any and all of the enclosures.

Lid filters reduce hydrogen in the drum head space, liners, and bags. Figure 3 illustrates the reduction in hydrogen provided by a lid filter with a porosity of 0.3 .

The effect of changing the lid filter porosity on gas concentration is shown in Figure 4. The lid filter porosity is constant at 0.5 from the beginning of the transient to day 360 . At day 360 the filter porosity instantaneously decreases from 0.5 to a constant of 0.1 . The hydrogen concentration increases substantially after day 360 . Allowing the lid filter porosity to change during a transient has been useful in determining the effect of water on the drums. Water in the filters tends to restrict flow through the filter, and is modeled as a decrease in the lid filter porosity.

\subsection{Quality Assurance}

The H2GAS program is currently non-critical software. It has been completed as NRTSC task no. 92-079-0. Due to uncertainty in input parameters and assumptions made in the model, the model is not currently well enough refined to be used as the sole determinant in finding the hydrogen gas concentration within transuranic waste drums. Results from H2GAS should not be applied in such a way that the consequences of a critical application are possible. 


\section{References}

(1) Acton, R. U., et. al. Effective Thermal Conductivity of Waste Forms (R804877); Sandia National Laboratories, February 1988.

(2) Cussler, E. L. Diffusion Mass Transfer in Fluid Systems, Cambridge University Press, 1984. pp. 108-118. 


\section{Appendix Al. \\ Example Execution of H2GAS}

SLLAB1 > run h2gas

\section{* program h2gas \\ - MODEL FOR HYDROGEN GAS CONCENTRATION \\ * LAST REVISED JULY 19, 1991}

Enter the name of the input data file: example.ttf

Enter a name for the pressure output file: example.out

Do you want to check for termination after every 10 printouts? $(Y / N): n$

Do you want to change the lid-filter permeability at some time? $(Y / N): n$

$G$ values ( $m o l e c u l e s$ of gas produced/100 ev):

$$
\begin{array}{lll}
\mathrm{H} 2 & : & 0.249 \\
\mathrm{CO} 2 & : & 0.008 \\
\infty & : & 0.004 \\
\mathrm{O} 2 & : & -0.110
\end{array}
$$

Total gas generation $G$ value: 0.261

\begin{tabular}{|c|c|c|c|c|c|c|c|}
\hline & & & & & & & \\
\hline & PSIG & $\mathrm{H} 2$ & $\mathrm{CO} 2$ & $\mathrm{CO}$ & 02 & $\mathrm{~N} 2$ & $\mathrm{H} 2 \mathrm{O}$ \\
\hline Bag 1 & 0.211 & 2.586 & 0.136 & 0.045 & 19.056 & 76.640 & 1.538 \\
\hline Liner 1 & 0.136 & 1.006 & 0.048 & 0.005 & 20.369 & 77.027 & 1.546 \\
\hline Drum 1 & 0.105 & 0.744 & 0.043 & 0.002 & 20.473 & 77.190 & 1.549 \\
\hline Enclosure 1 & 0.000 & 0.000 & 0.040 & 0.000 & 20.660 & 77.740 & 1.560 \\
\hline Enclosure 2 & 0.000 & 0.000 & 0.040 & 0.000 & 20.660 & 77.740 & 1.56 \\
\hline & Total $p$ & ure a & s mole & ent: & days & & \\
\hline & PSIG & $\mathrm{H} 2$ & $\mathrm{CO} 2$ & $\mathrm{CO}$ & $\mathrm{O} 2$ & N2 & \\
\hline Bag 1 & 0.360 & 4.656 & 0.225 & 0.086 & 17.635 & 75.876 & 1.5 \\
\hline Liner 1 & 0.341 & 2.562 & 0.065 & 0.015 & 19.856 & 75.977 & 1.5 \\
\hline Drum 1 & 0.296 & 2.152 & 0.053 & 0.009 & 20.054 & 76.203 & 1.5 \\
\hline Enclosure 1 & 0.000 & 0.000 & 0.040 & 0.000 & 20.660 & 77.740 & 1.5 \\
\hline Enclosure 2 & 0.000 & 0.000 & 0.040 & 0.000 & 20.660 & 77.740 & 1.56 \\
\hline
\end{tabular}

Are these $G$ values acceptable? $Y(Y / N): y$

\begin{tabular}{lcrrrrrr} 
& & \multicolumn{7}{c}{ Total pressure and gas mole percent at steady-state } \\
& PSIG & $\mathrm{H} 2$ & $\mathrm{CO2}$ & \multicolumn{1}{c}{ CO } & \multicolumn{1}{c}{ O2 } & N2 & $\mathrm{H} 2 \mathrm{O}$ \\
Bag 1 & 3.061 & 27.893 & 4.720 & 1.755 & 0.000 & 64.341 & 1.291 \\
Liner 1 & 1.847 & 24.477 & 3.689 & 1.384 & 0.000 & 69.064 & 1.386 \\
Drum 1 & 1.455 & 23.069 & 3.479 & 1.295 & 0.000 & 70.737 & 1.419 \\
Enclosure 1 & 0.000 & 0.008 & 0.041 & 0.000 & 20.648 & 77.743 & 1.560 \\
Enclosure 2 & 0.000 & 0.003 & 0.040 & 0.000 & 20.655 & 77.741 & 1.560
\end{tabular}

Total pressure and gas mole percent: 15.000 days 
Appendix A2.

Example Input File

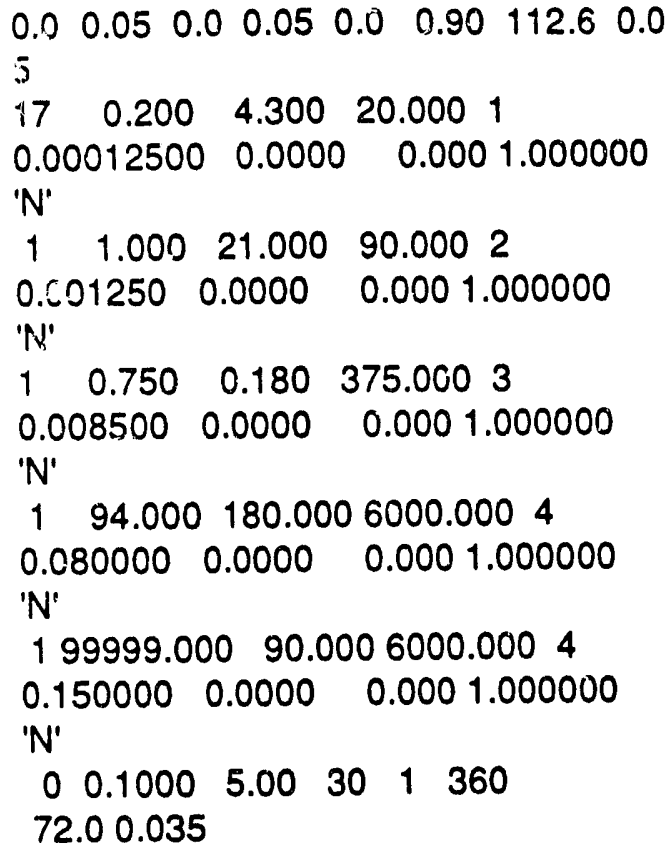


Appendix B1.

Example Output Pressure Results File

Waste Material Composition

Cellulose

Polyethylene

Latex

Polyvinylchloride

Plexiglass

Inert material

Plutonium Curies
Gas Generation Values

$\begin{array}{lc}\text { Hydrogen } & 0.249 \\ \text { Carbon dioxide } & 0.008 \\ \text { Carbon monoxide } & 0.004 \\ \text { Oxygen } & -0.110 \\ \text { H2-drum(mL/day) } & 0.000\end{array}$

Drum Physical Parameters:

$\begin{array}{llll}\text { Number } & \begin{array}{l}\text { Volume } \\ (\mathrm{cu} \mathrm{ft})\end{array} & \begin{array}{c}\text { Area } \\ (\mathrm{sq} \mathrm{ft})\end{array} & \begin{array}{l}\text { Thickness } \\ \text { (mil) }\end{array}\end{array}$

$\begin{array}{llrrrrr}\text { Bag 1 } & 17 & 0.20 & 4.30 & 20.00 & 0.125 \mathrm{E}-03 & \mathrm{~N} \\ \text { Liner 1 } & 1 & 1.00 & 21.00 & 90.00 & 0.125 \mathrm{E}-02 & \mathrm{~N} \\ \text { Drum 1 } & 1 & 0.75 & 0.18 & 375.00 & 0.850 \mathrm{E}-02 & \mathrm{~N} \\ \text { Enclosure 1 } & 1 & 94.00 & 180.00 & 6000.00 & 0.800 \mathrm{E}-01 & \mathrm{~N} \\ \text { Enclosure 2 } & 1 & 99999.00 & 90.00 & 6000.00 & 0.150 \mathrm{E}+00 & \mathrm{~N}\end{array}$

Pressure (Atm) when drum lid lifts off gasket: 5.00

Total pressure and gas mole percent at steady-state

$\begin{array}{lrrrrrrr} & \text { PSIG } & \text { H2 } & \text { CO2 } & \text { C } & \text { O2 } & \text { N2 } & \text { H2O } \\ & & & & & & & \\ \text { Bag 1 } & 3.061 & 27.893 & 4.720 & 1.755 & 0.000 & 64.341 & 1.291 \\ \text { Liner 1 } & 1.847 & 24.477 & 3.689 & 1.384 & 0.000 & 69.064 & 1.386 \\ \text { Drum 1 } & 1.455 & 23.069 & 3.479 & 1.295 & 0.000 & 70.737 & 1.419 \\ \text { Enclosure 1 } & 0.000 & 0.008 & 0.041 & 0.000 & 20.648 & 77.743 & 1.560 \\ \text { Enclosure 2 } & 0.000 & 0.003 & 0.040 & 0.000 & 20.655 & 77.741 & 1.560\end{array}$

Total pressure and gas mole percent: 15.000 days

$\begin{array}{lccccccc} & \text { PSIG } & \text { H2 } & \text { CO2 } & \text { CO } & \text { O2 } & \text { N2 } & \text { H2O } \\ & & & & & & & \\ \text { Bag 1 } & 0.211 & 2.586 & 0.136 & 0.045 & 19.056 & 76.640 & 1.538 \\ \text { Liner 1 } & 0.136 & 1.006 & 0.048 & 0.005 & 20.369 & 77.027 & 1.546 \\ \text { Drum 1 } & 0.105 & 0.744 & 0.043 & 0.002 & 20.473 & 77.190 & 1.549 \\ \text { Enclosure 1 } & 0.000 & 0.000 & 0.040 & 0.000 & 20.660 & 77.740 & 1.560 \\ \text { Enclosure 2 } & 0.000 & 0.000 & 0.040 & 0.000 & 20.660 & 77.740 & 1.560\end{array}$


Non-critical data pg 10 of 22

\author{
Appendix B1. \\ Example Output Pressure Results File \\ (continued)
}

Total pressure and gas mole percent: 30.000 days

$\begin{array}{lccccccr} & \text { PSIG } & \text { H2 } & \text { CO2 } & \text { CO } & \text { O2 } & \text { N2 } & \text { H2O } \\ \text { Bag 1 } & 0.360 & 4.656 & 0.225 & 0.086 & 17.635 & 75.876 & 1.523 \\ \text { Liner 1 } & 0.341 & 2.562 & 0.065 & 0.015 & 19.856 & 75.977 & 1.525 \\ \text { Drum 1 } & 0.296 & 2.152 & 0.053 & 0.009 & 20.054 & 76.203 & 1.529 \\ \text { Enclosure 1 } & 0.000 & 0.000 & 0.040 & 0.000 & 20.660 & 77.740 & 1.560 \\ \text { Enclosure 2 } & 0.000 & 0.000 & 0.040 & 0.000 & 20.660 & 77.740 & 1.560\end{array}$

Maximum Concentration

$\begin{array}{rlr}\text { Enclosure } & \text { Mole Percent } & \text { Time (days) } \\ \text { Bag 1 } & 4.656 & 30.000 \\ \text { Liner 1 } & 2.562 & 30.000 \\ \text { Drum 1 } & 2.152 & 30.000 \\ \text { Enclosure 1 } & 0.000 & 30.000 \\ \text { Enclosure 2 } & 0.000 & 30.000\end{array}$




\section{Appendix B2. \\ Example Gas Flux Ouput File}

Day $=0.000$

H2 Gas Flux

(moles/hr-ft*ft)

$\begin{array}{ll}\text { Bag 1 } & : \\ \text { Liner 1 } & : \\ \text { Drum 1 } & : \\ \text { Enclosure 1 } & \text { Enclosure 2 }\end{array}$

Day $=15.000$
$0.10 E-07$

$0.36 \mathrm{E}-07$

0.42E-05

$0.45 \mathrm{E}-08$

$0.98 E-08$
H2 Transport Agents

Permeation

Diffusion

(material)

Diffusion

(filter)

$59.83 \%$
$8.45 \%$
$0.32 \%$
$0.00 \%$
$0.00 \%$

$40.17 \%$

$91.55 \%$

$99.68 \%$

$100.00 \%$

$100.00 \%$
$0.00 \%$
$0.00 \%$
$0.00 \%$
$0.00 \%$
$0.00 \%$

$\begin{array}{rrr}59.83 \% & 40.17 \% & 0.00 \% \\ 8.45 \% & 91.55 \% & 0.00 \% \\ 0.32 \% & 99.68 \% & 0.00 \% \\ 0.00 \% & 100.00 \% & 0.00 \% \\ 0.00 \% & 100.00 \% & 0.00 \%\end{array}$

Day $=\quad 30.000$

$\begin{array}{lll}\text { Bag 1 } & : & 0.36 \mathrm{E}-08 \\ \text { Liner 1 } & : & 0.69 \mathrm{E}-08 \\ \text { Drum 1 } & : & 0.36 \mathrm{E}-06 \\ \text { Enclosure 1 } & : & 0.38 \mathrm{E}-09 \\ \text { Enclosure 2 } & : & 0.21 \mathrm{E}-10\end{array}$

$\begin{array}{rrr}59.83 \% & 40.17 \% & 0.00 \% \\ 8.45 \% & 91.55 \% & 0.00 \% \\ 0.32 \% & 99.68 \% & 0.00 \% \\ 0.00 \% & 100.00 \% & 0.00 \% \\ 0.00 \% & 100.00 \% & 0.00 \%\end{array}$




\section{Appendix B3 \\ Example Temperature Output File}

\section{DRUM TEMPERATURE}

\section{INPUT VALUES}

Thermal conductivity (Btu/hr-ft):

Surface Temperature (F):

0.035

Plutonium Curies :

72.00

100.0

\section{OUTPUT VALUES}

Average temperature $\left({ }^{\circ} \mathrm{F}\right)=$

76.7

Centerline temperature $\left({ }^{\circ} \mathrm{F}\right)=$

81.5 


\title{
Appendix C. Description of H2GAS Subroutines
}

\begin{abstract}
ANSWER
Ensure that answer to 'yes' or 'no' question is ' $y$ ', ' $Y$ ', ' $n$ ', or ' $N$ ' and convert lower case to upper case characters.

FLUX

Calculate relative percentages of gas flux through barriers and filters due to permeation and diffusion.

\section{TEMP}

Calculates average drum temperatures based upon $\mathrm{Pu}-238$ loading, outside environment temperature, and thermal conductivity of waste.

\section{DIEUS}

Determines temperature dependent diffusion coefficients based upon a Chapman-Enskog temperature correlation.
\end{abstract}

\section{MODGEN}

Allows user to override calculated $G$ values by entering experimentally obtained values.

\section{CRUNCH}

Solves the gas diffusion equations for transient gas concentrations. The equations form a tridiagonal matrix and are solved by back substitution.

\section{DIFFVAL}

Compute diffusion and permeation values for the diffusion equations.

\section{DIFUS}

Calculate diffusion coefficients for hydrogen, carbon monoxide, carbon dioxide, nitrogen, and oxygen through the air.

\section{DRUMREL}

Relieve the drum pressure if it is above the allowed maximum.

\section{FILEOUT}

Print the results to the specified output file.

\section{FLAGMAT}

Flag each time the material changes.

\section{ELOW}

Adjust volume pressures and gas concentrations for filter flow.

\section{FLUX}

Write to file 'FLX.DAT' gas fluxes and mass transport agent percentages.

\section{GVALU}

Calculate gas generation rate per time increment.

PRNOUT

Determine printout times and print results to terminal. 


\section{Appendix C. \\ Description of H2GAS Subroutines \\ (continued)}

READIN

Read input values from the specified input data file.

RECOMB

Adjust concentrations for recombination reactions.

\section{RUNDATA}

Prompt user for input and output filenames, program termination after every 10 printouts, and changing lid permeability at some time.

\section{SETUP}

Data statements to initialize arrays and constants.

\section{SSORTR}

Find temperature of drum waste and set time variables if run is steady-state only.

\section{TEMP}

Calculate average and centerline drum temperature.

\section{STEADY}

Find steady-state solutions to gas partial pressures.

\section{TIMVAR}

Calculate time variables for transient runs.

\section{TRANSIENT}

Controls irterations to find solutions to transient gas partial pressures.

WRITEIN

Write the user input data to output file. 


\section{Appendix D. \\ Variables and Parameters in H2GAS}

Parameters

$\begin{aligned} \text { IG } & =\text { gas species produced from radiolysis }(4) \\ \text { IN } & =\text { maximum number of enclosures }(15) \\ \text { JG } & =\text { number of gas species }(6)\end{aligned}$

Real

$\begin{array}{ll}\text { FXI } & =\mathrm{ICV}^{*} \\ \mathrm{RI}(\mathrm{IN}, \mathrm{JG}) & =\mathrm{ICV} \\ \mathrm{RXN} & =\text { hydrogen consumed by recombination }(\mathrm{atm}) \\ \text { SUMGEN } & =\text { in steady-state calculation, summary of } \mathrm{lb} \text {-moles } \\ & \text { of all species of gas over all regions. }\end{array}$

Logical

FILCHG = true if filter is changed on day DAYC

Character

A3 $=$ prompt for terminating printout after every 10 timesteps.

A4 $=$ prompt to change the lid filter permeability.

A6 $\quad=$ prompt to change gas generation values.

ANS $\quad=\mathrm{Y}$ or $\mathrm{N}$ for queries

CONTA = type of container (bag, liner, drum, enclosure 1, enclosure2)

$\mathrm{GAS} \quad=$ type of gas $(\mathrm{H} 2, \mathrm{CO} 2, \mathrm{CO}, \mathrm{O} 2, \mathrm{~N} 2, \mathrm{H} 20)$

INFIL $\quad=$ input filename

OUTFIL = output filename

REC $=\mathrm{Y}$ or $\mathrm{N}$ for recombiner

Integer

IST

$=$ number of first enclosure with filter going from inside to outside.

$\mathrm{L}=$ transient time counting variable

LB = counter for number of concentric bags

LD = counter for number of concentric drums

LL $\quad=$ counter for number of concentric liners

$\mathrm{M}(\mathrm{IN}) \quad=$ index for type of barrier

MAXDAY $=$ duration of calculation or 0 for steady-state (days)

$\mathrm{N}(\mathrm{IN}) \quad=$ number of containers

NFT $=$ number of volumes connected by filters

NGAS $=$ number of gas species

NHOUR $=$ number of hours between printouts

$\mathrm{NM} \quad=$ number of barriers

$\mathrm{NP} \quad=$ counter to check for number of printout times.

NPRINT $=$ number of calculations between printouts.

$\mathrm{NT}=$ number of calculations per hour (calculations/hour)

Real

$\begin{array}{ll}\mathrm{A}(\mathrm{IN}) & =\text { area of container }\left(\mathrm{ft}^{2}\right) \\ \mathrm{B}(\mathrm{IN}+1) & =\text { filter area }\left(\mathrm{in}^{2}\right) \\ \mathrm{C}(\mathrm{IN}) & =\mathrm{ICV}^{*} \\ \mathrm{CEL} & =\text { mass fraction of cellulose }\end{array}$




\section{Appendix D. \\ Variables and Parameters in H2GAS \\ (continued)}

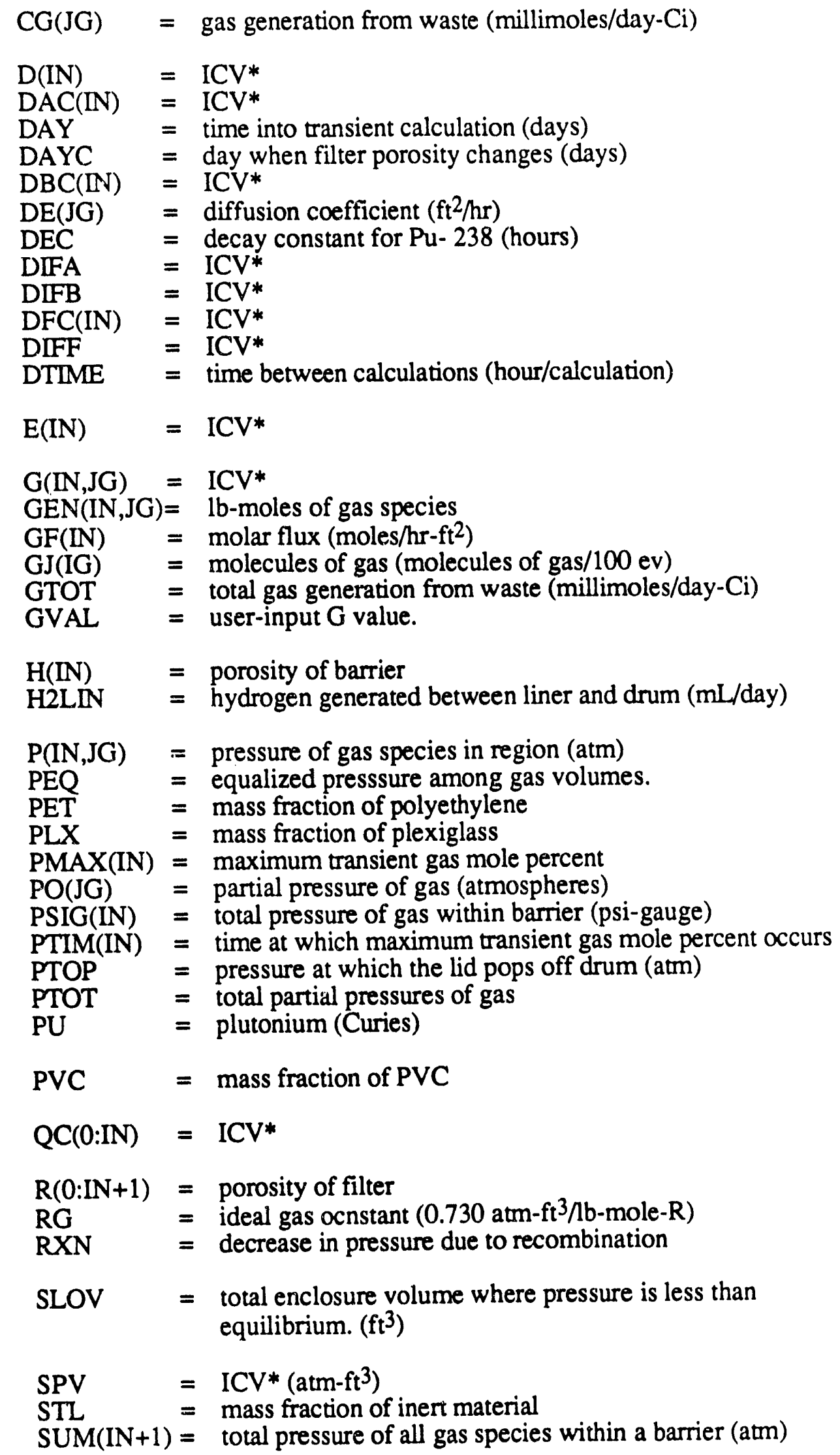




\section{Appendix D. \\ Variables and Parameters in H2GAS \\ (continued)}

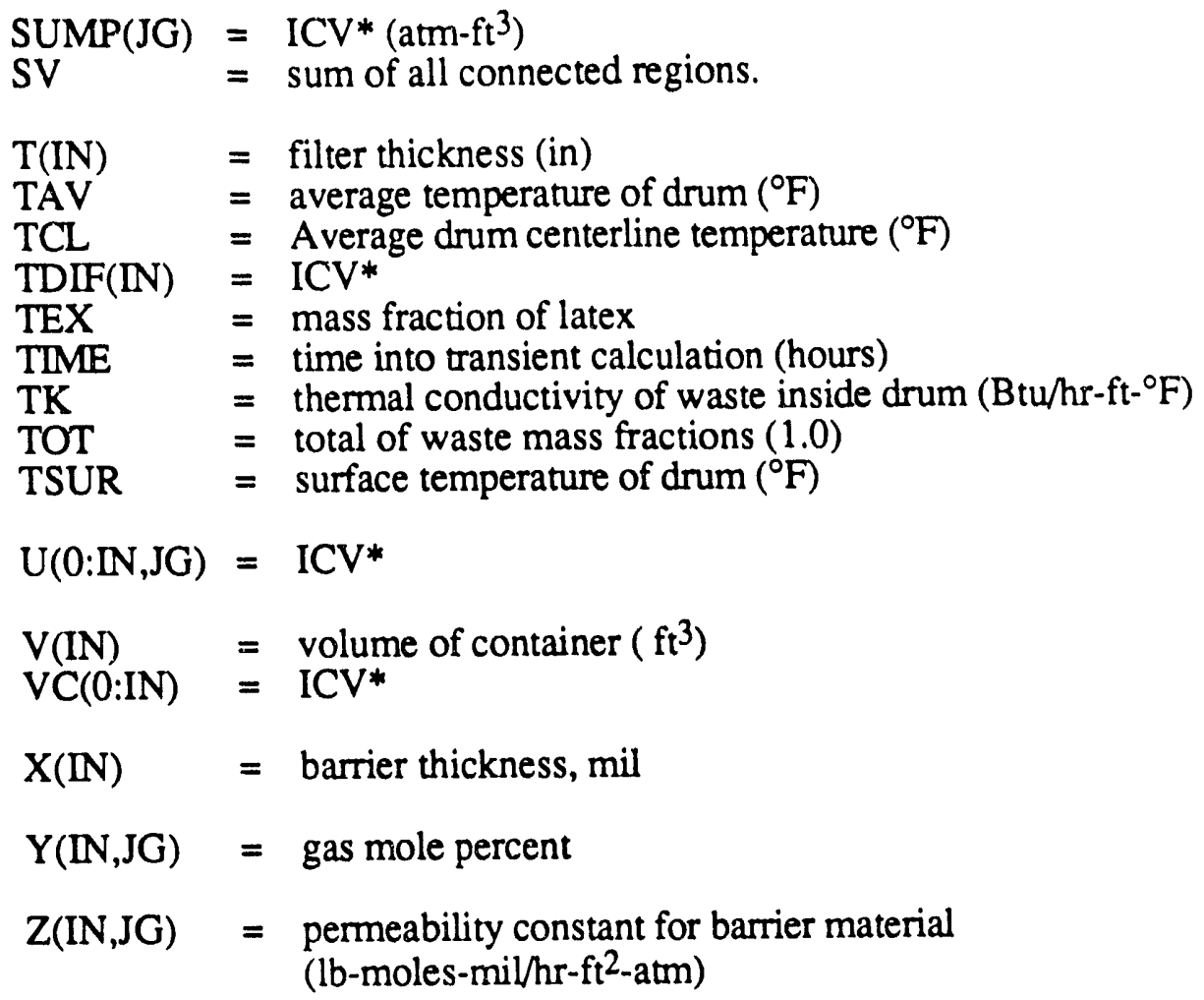

* ICV refers to an intermediate computed value with no physical significance 


\section{Appendix E.}

Constants for Converions in H2GAS

Convert curies of plutonium into lb-moles (Subroutine GVALU) :

$$
9.186(10)^{-3} \mathrm{lb}-\text { moles }=\mathrm{CG}(\mathrm{i})\left(10^{-3}\right)\left(\frac{\text { gmoles }}{\text { day-Ci }}\right)(\mathrm{Ci})(\mathrm{hr})\left(\frac{1 \text { day }}{24 \text { hours }}\right)\left(\frac{\mathrm{lb}_{\mathrm{m}} \text { :'nole }}{453.6 \text { gmoles }}\right)
$$

Convert half-life of Pu-238 into hours ${ }^{-1}$ :

$$
9.1519 \mathrm{E}-07 \mathrm{hrs}=\frac{\ln 2}{86.4 \text { years }}\left(\frac{1 \text { year }}{365.25 \text { days }}\right)\left(\frac{1 \text { day }}{24 \text { hours }}\right)
$$

Convert millimoles of gas per day per curie into molecules per $100 \mathrm{eV}$ :

$$
\begin{aligned}
\frac{3.432 \text { molecules }}{100 \mathrm{eV}}= & \mathrm{CG}(\mathrm{i})\left(10^{-3}\right)\left(\frac{\text { gmoles }}{\text { day-Ci }}\right)\left(\frac{6.0226(10)^{23} \text { molecules }}{\text { mole }}\right)\left(\frac{\mathrm{Ci}}{3.7(10)^{10} \frac{\text { disintegrations }}{\text { second }}}\right) \\
& \left(\frac{1 \text { disintegration }}{5.15(10)^{6} \mathrm{eV}}\right)\left(\frac{\text { day }}{86400 \text { seconds }}\right)
\end{aligned}
$$




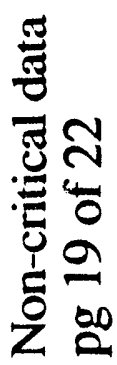

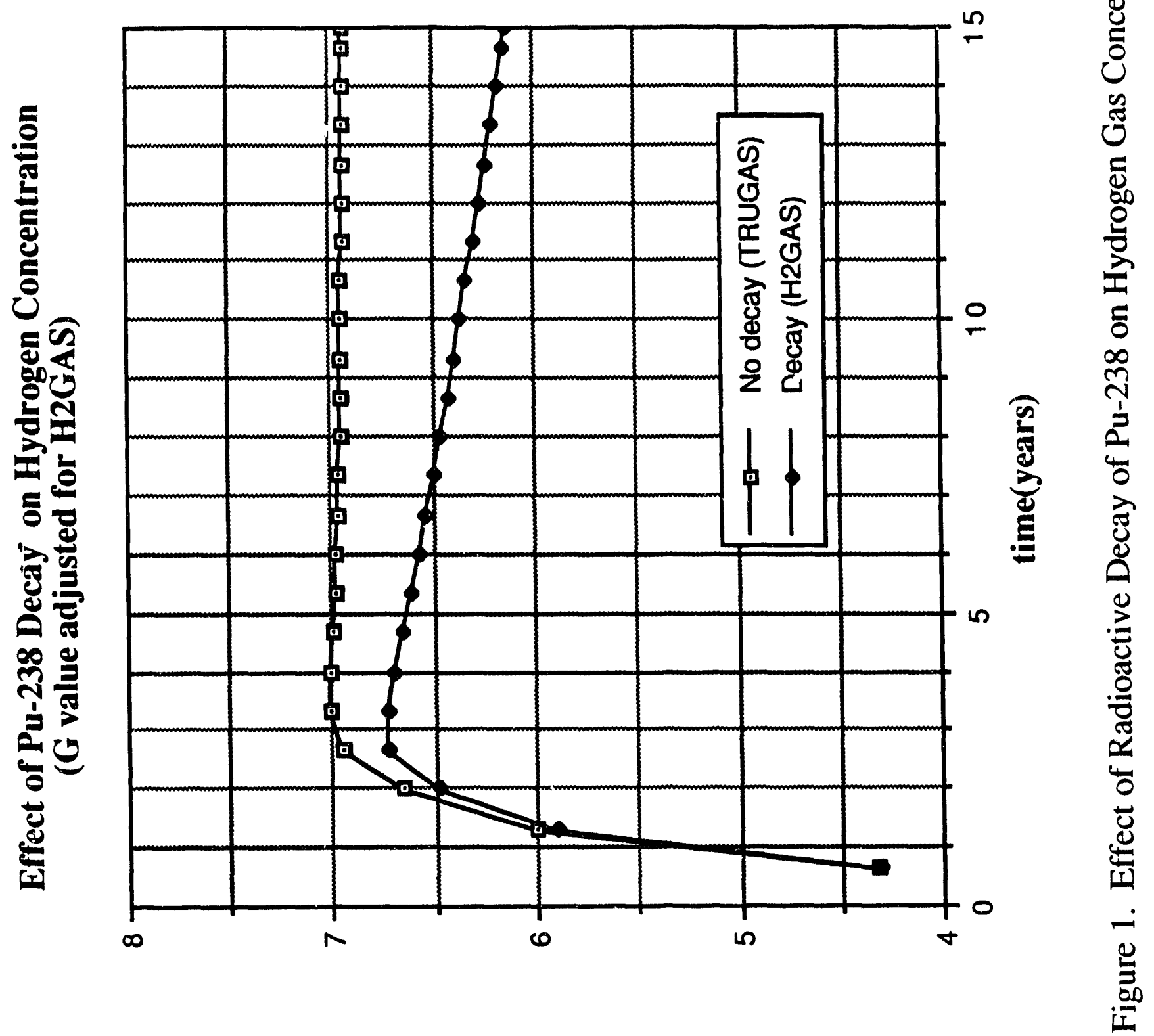

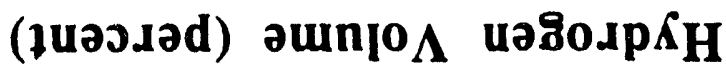




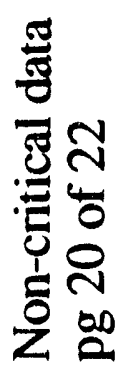

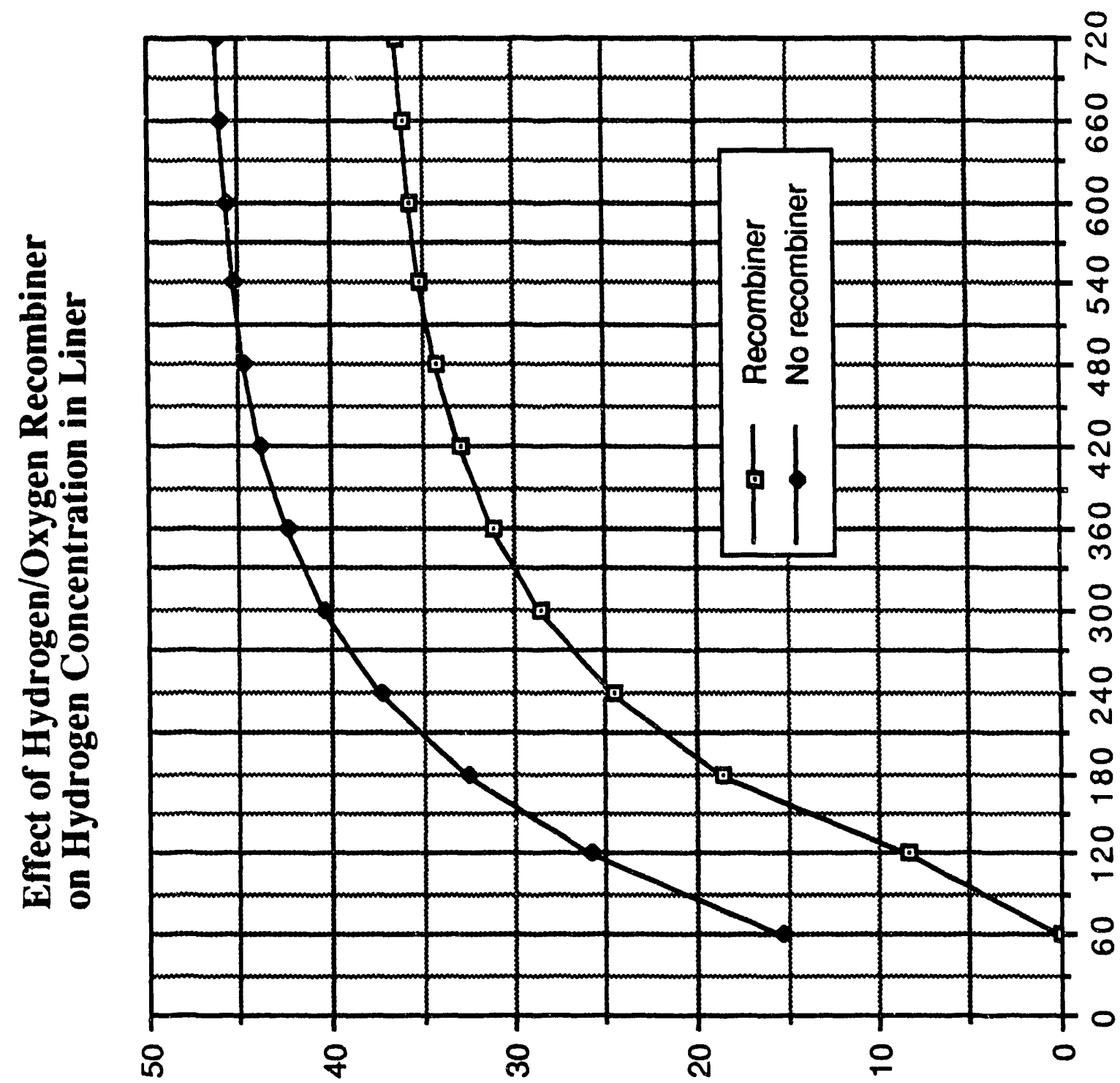


承
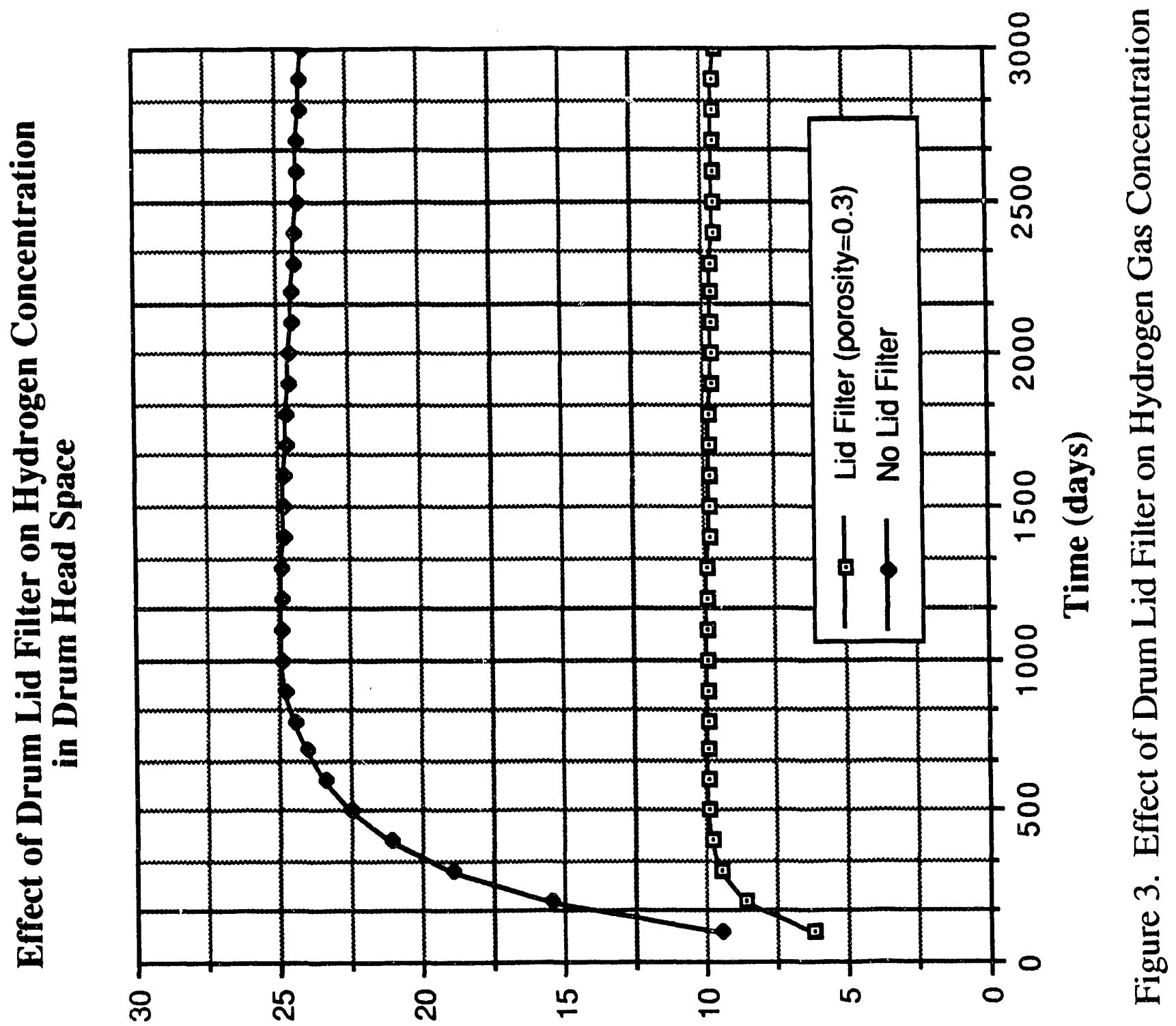

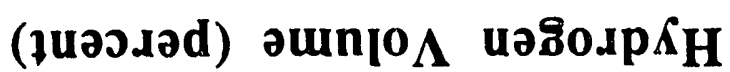


종

즈

苟

บN

Z

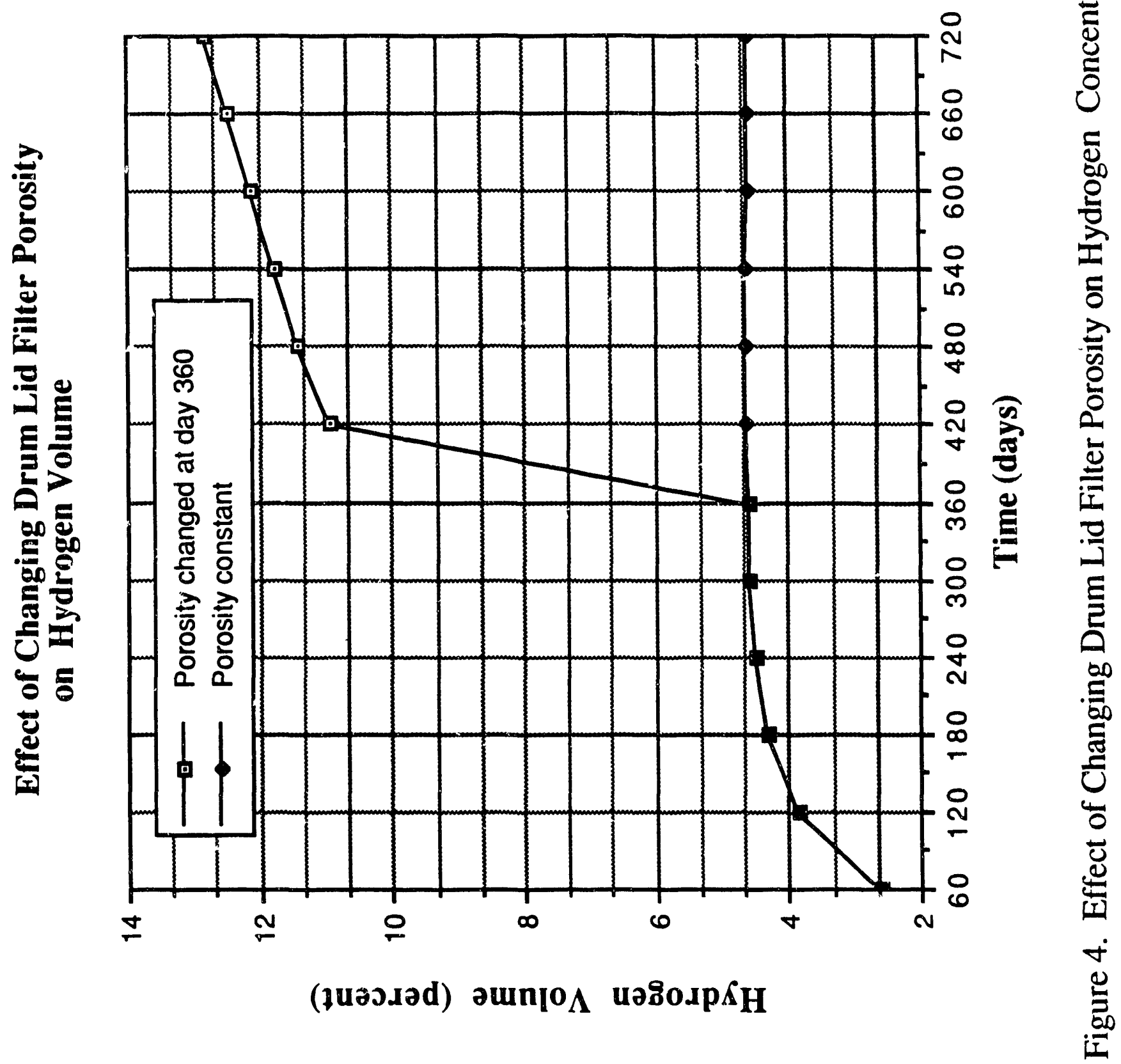



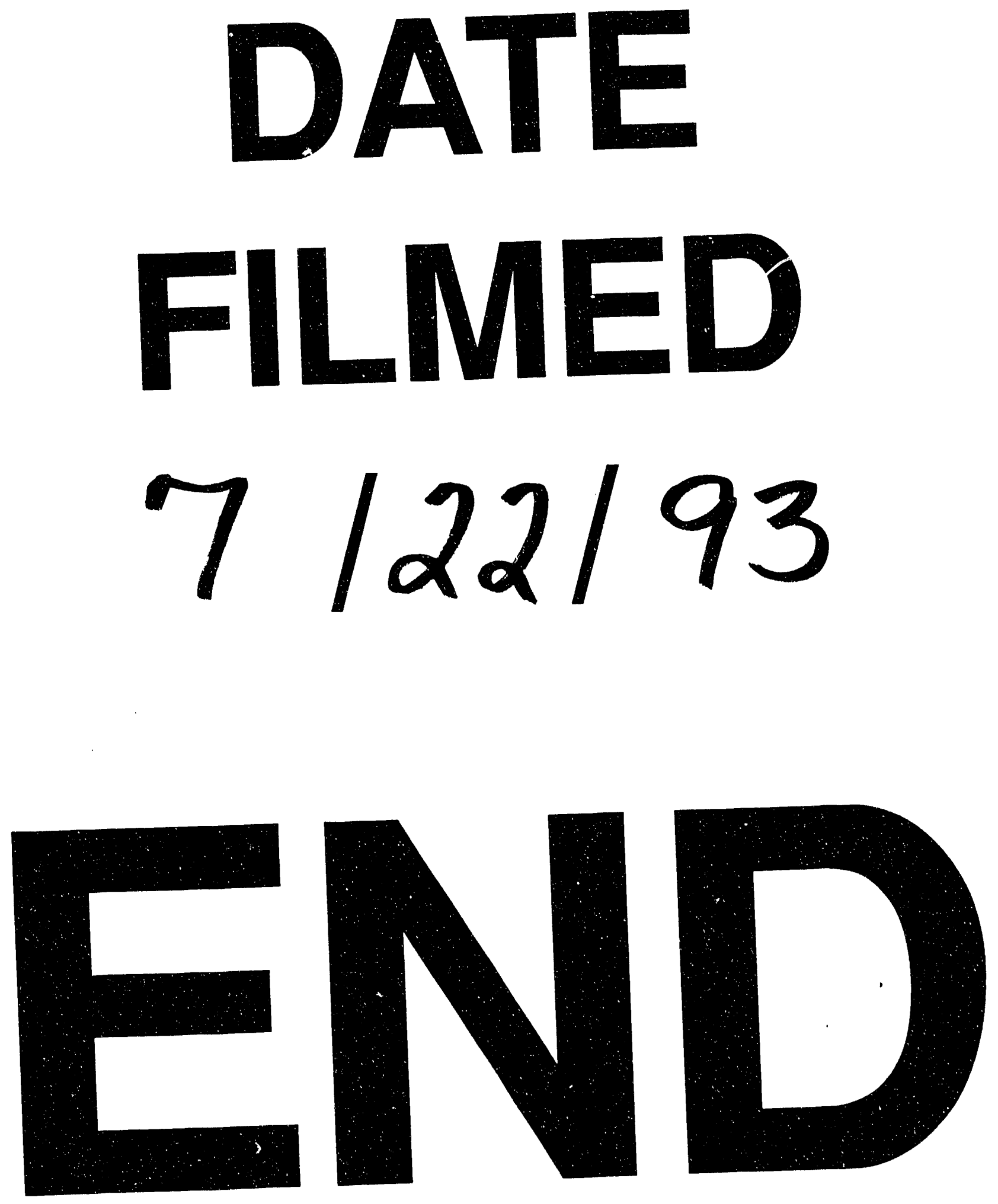
